\title{
Entre la legalidad e ilegalidad de los cultivos de coca en Colombia: Realidades desde el corregimiento de El Plateado, municipio de Argelia Cauca
}

\section{Between legality and illegality of coca crops in Colombia: realities from the village of the Silver, Municipality of Algeria Cauca}

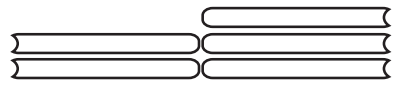

Denis Antonio Arboleda Suarez ${ }^{1}$

Recibido: noviembre 2016 Aprobado: mayo 2017

\section{Resumen}

El siguiente artículo es parte de los resultados de una investigación realizada en el marco de la tesis de Maestría en Desarrollo Comunitario Sustentable de la Universidad Nacional de Costa Rica, titulada Identidades, proyectos de vida y participación comunitaria de jóvenes en el corregimiento de El Plateado, municipio de Argelia Cauca -Colombia. En el documento, en primera instancia se hace una breve descripción de los aspectos metodológicos utilizados en campo durante la fase de indagación; seguido, se presenta un rápido recorrido sobre los antecedentes históricos de los cultivos de uso ilícito en Colombia, en especial los relacionados con el cultivo de coca. Posteriormente, se realiza una contextualización frente a los sucesos históricos de la fundación del corregimiento de El Plateado, para luego adentrarse en los acontecimientos históricos de la llegada, establecimiento y expansión de los cultivos de coca en el escenario local. Finalmente se discute frente a los cambios socioculturales sucedidos en el corregimiento por causa del desarrollo de una economía catalogada como ilícita por el Estado y se efectúan algunos comentarios finales frente a lo ilícito y la importancia de la historia local como espacio para la reconstrucción de la memoria colectiva.

Palabras clave: Coca, cultivos ilícitos, narcotráfico, historia local.

\section{Abstract}

The following article is part of the results of research conducted within the framework of the Master's thesis in Sustainable Community Development National University of Costa Rica, entitled 'Identities, life projects and community participation of young

1 Ing. Agropecuario - Universidad del Cauca, Colombia. Docente Institución Educativa Técnica Zapata. dearsua@hotmail.com 
people in the township of the Silver, Municipality of Algeria Cauca-Colombia. " The document in the first instance a brief description of the methodological aspects used in the field during the inquiry, followed by a quick tour on the historical background of illicit crops in Colombia is presented, especially those related is coca cultivation. Subsequently, a contextualization is performed against the historical events of the founding of the village of El Silver, then enter the historical events of arrival, establishment and expansion of coca cultivation in the local scene. Finally discussed against the occurred sociocultural changes in the district because of the development of a classified as illegal by the State economy and some concluding remarks are made against the illicit and the importance of local history as a space for memory reconstruction collective.

Keywords: coca, illicit crops, drug trafficking, local history

\section{Introducción}

Desde hace ya varios décadas, Colombia se ha configurado a nivel mundial en uno de los principales países productores y exportadores de cocaína y pese a los esfuerzos del gobierno nacional por controlar la producción de hoja de coca con la aplicación de la política antidrogas, los resultados no han sido alentadores; al contrario, las áreas cultivadas, en lugar de disminuir se han incrementado durante los últimos años y los departamentos del sur del país son los que más contribuyen para el abastecimiento de esta economía ilegal.

Los departamentos del sur de país (Nariño, Cauca, Putumayo y Caquetá) y Catatumbo constituyen el principal reto para enfrentar el problema de la producción de cocaína. Allí no solo se encuentra la mayoría de los cultivos de coca (73\%), también existen condiciones de vulnerabilidad muy fuertes que limitan la confianza de las comunidades en el Estado. (UNODC, 2015, p. 13)

Así, para entender las dinámicas socioculturales, políticas, económicas y ecológicas que se desarrollan al interior de los territorios locales que han sido afectados y que aún viven el flagelo de los denominados cultivos de uso ilícito, caso específico de los cultivos de coca, es necesario dar una mirada en el panorama nacional para ubicar los principales momentos en la historia del país que condujeron a que un número significativo de campesinado y a la vez otra serie de actores que hacen parte de estas economías, terminaran por hacer de la coca una alternativa y forma de vida frente a la desesperanza en aquellos 
territorios con poca presencia estatal en materia de inversión social y económica. A su vez, es imprescindible indagar en el escenario local desde las voces de sus propias poblaciones el conjunto de sucesos históricos que condujeron a la transformación sociocultural de un territorio que, en principio, sustentó su base económica a partir de cultivos no proscritos por el Estado.

Para el caso concreto del corregimiento El Plateado, ubicado en el municipio de Argelia Cauca, la vida de su población ha sido atravesada por la presencia de cultivos de coca desde hace más de 30 años, lo que ha configurado un espacio conflictivo en donde las ideas, valores y prácticas dominantes de la gente se encuentran mediadas por la actividad económica del narcotráfico.

La zona está caracterizada, en gran parte, por la presencia de grupos colonos provenientes de varias regiones del país motivados por las promesas del mercado ilícito o que huyen de la violencia política que padece con mayor rigor el campo colombiano. Estos promueven, en el caso del narcotráfico, valores y actitudes propios de las economías de bonanza donde el dinero sustituye otros elementos de articulación social, establecen relaciones de dependencia económica y fortalecen la idea de que la organización social es innecesaria para mejorar las condiciones de vida, situación que tiene consecuencias negativas a nivel comunitario. Ahora bien, la movilidad permanente de población que matiza el patrón de poblamiento enriquece, con sus prácticas, creencias y costumbres, la trama social; pero también representan un obstáculo para la estructuración en el tiempo de una cultura local, toda vez que son necesarios mínimos de permanencia que garanticen vínculos comunitarios y territoriales.

Desde una mirada general, en el territorio tiene lugar el encuentro de muchas personas provenientes de departamentos como el Putumayo, Caquetá, Nariño, Huila, Valle del Cauca, Antioquia, entre otros, las cuales en su mayoría se anclan en la economía local en calidad de raspachines, personajes a quienes se puede describir como individuos que tienen como principal sustento económico la cosecha de hojas de coca. También existen quienes se insertan en el mercado laboral local como ayudantes de laboratorios en actividades de procesamiento de coca, sujetos intermediarios en la compra de hoja de coca, entes distribuidores de insumos químicos etc., pero también existe una mínima proporción de la población que se dedica a otro tipo de actividades que no se relacionan directamente con los cultivos de uso ilícito. Es en este escenario declarado ilegal por el Estado, en el cual tuvo lugar la indagación frente a los sucesos históricos que dieron lugar al desarrollo de una economía que se ha convertido en el sustento económico principal para muchas 
comunidades campesinas de sectores rurales colombianos marginados por la escasa atención del Estado.

\section{Aspectos metodológicos para el desarrollo de la investigación}

La investigación corresponde a la tipología de estudios de carácter cualitativo, en el cual la revisión documental, la observación participante, el diálogo con informantes clave, relatos de vida y los grupos de discusión, fueron herramientas que se convirtieron en importantes elementos para describir el desarrollo sociohistórico derivado de la presencia de cultivos de uso ilícito en el corregimiento de El Plateado.

En principio se acudió a la revisión documental de textos y archivos periodísticos disponibles en periódicos como El Espectador, Diario Proclama del Cauca, El Liberal y El Tiempo, en los cuales se buscó información relacionada con el desarrollo de los cultivos de coca en Colombia para ubicar los principales sucesos históricos que incidieron en su expansión hacia el sur occidente del país y en el caso concreto de la investigación, su llegada al corregimiento El Plateado.

Posteriormente, se revisó un texto autoría de uno de los fundadores de El Plateado para tener una idea general sobre el origen del corregimiento, para luego indagar en campo a informantes clave que han vivido por varios años y conocen muy bien la historia de la llegada y expansión de los cultivos de coca en la localidad. La "bola de nieve" fue una estrategia valiosa para identificar a los informantes con quienes se establecieron los diálogos.

Se entrevistó a un total de 10 personas con las cuales se acordaron, de manera concertada, los momentos de encuentro y se realizaron dos talleres participativos para la reconstrucción de la memoria colectiva, en los cuales participaron personas jóvenes y adultas pertenecientes al programa 3011 de la Institución Educativa Técnica Miguel Zapata. Los relatos de vida de dos habitantes de la comunidad también fueron claves para comprender, desde sus narrativas, el desarrollo histórico de los cultivos de coca en el escenario local. La información obtenida fue contrastada con archivos periodísticos para tener una radiografía más completa de la dinámica sociohistórica desarrollada en el marco de lo ilícito en el corregimiento. 


\section{Antecedentes históricos de los cultivos de uso ilícito: Entre la legalidad y la ilegalidad de los cultivos de coca en Colombia}

El tema de los cultivos de uso ilícito no es algo nuevo en el país, más bien es un proceso de varias años en el cual se han visto inmersos diferentes actores desde los pequeños, medianos y grandes productores de hoja de coca, hasta grupos armados al margen de la ley, como los grupos guerrilleros y paramilitares; pero también el mismo Estado, que por la ausencia de unas políticas de desarrollo rural claras que verdaderamente beneficien el interés de las clases populares campesinas, afrodescendientes e indígenas más desfavorecidas, propició el medio de cultivo para que germinaran y se desarrollaran economías regionales de lo catalogado como ilícito. Como lo expresan Ferro, Uribe, Osorio y Castillo (1999), el narcotráfico no es más que la expresión de "la descomposición del Estado" (p. 3) y lógicamente, los cultivos de coca terminaron supliendo la ausencia estatal en la garantía de condiciones para la generación de unos ingresos económicos significativos en las economías campesinas.

Hay que reconocer, en primer lugar, que la coca no siempre fue vista como algo ilegal y que no siempre ha hecho parte de las economías ilícitas del narcotráfico, ya desde la época prehispánica se tienen evidencias de que las comunidades indígenas de América la utilizaban como medicina y también en sus rituales de armonización junto a la Madre Tierra, rituales de los cuales muchos aún perduran en la memoria colectiva y en las prácticas de vida de los grupos indígenas actuales. Vidart (como se citó en Madariaga, 2006) afirma que la coca fue considerada como una planta sagrada a lo largo de los Andes del Sur de América, ocupando un importante lugar en la cosmogonía indígena. La misma autora menciona que una vez sucedida la invasión española, esta planta sagrada para los pueblos indígenas fue llevada hasta Europa y a partir de 1860 se sintetizaron una serie de extractos con fines medicinales y, a su vez, se dio el descubrimiento de sus propiedades anestésicas que posteriormente darían origen a la perversión de uso por su potencialidad como narcótico.

Es claro también que durante el periodo colonial la coca fue utilizada como instrumento de dominación y explotación de la fuerza laboral de los indígenas, tal como lo señala Parra (2014):

Durante el tiempo de la dominación española, el hábito de la masticación de las hojas de coca se difundió en toda la población indígena, perdiendo así su carácter mágico religioso llegando a ser utilizada como un elemento de expoliación y abuso, como pago por parte del salario de los trabajadores de las minas. (p 91) 
Antes del periodo denominado la colonia, los grupos indígenas ya usaban la coca como planta sagrada en sus rituales. Rivera (1998) menciona que a la llegada de los españoles esta planta ya era utilizada por diferentes culturas indígenas, como la quimbaya del actual departamento de Risaralda y también de los pueblos indígenas ubicados en territorios de los actuales departamentos del Valle del Cauca, Antioquia, Caldas, Magdalena, Guajira, Bolívar, Cundinamarca, Cauca, Huila y Nariño. Con el establecimiento de instituciones coloniales como la encomienda, la coca se convirtió en un medio de tributación.

Los colonizadores españoles, conocedores de los mecanismos de tributación empleados por los caciques, como también de los productos de preferencia para el tributo, reprodujeron las formas tributarias ancestrales renovadas y orientadas hacia unas nuevas formas de explotación, siendo esta la explicación del porque el tributo con coca fue auspiciado e incentivado por ellos. (Rivera, 1998, p. 148)

Así, de ser una planta sagrada que permitía colocar en contacto armónico el ser indígena con la naturaleza, su uso fue prostituido por el sujeto blanco europeo, cuyo interés único era explotar las riquezas existentes en América y con ello también el despojo de la libertad y ruptura de la espiritualidad indígena.

Los cultivos de coca, en su dimensión de ilegalidad, también tienen una estrecha relación con el desarrollo del narcotráfico y su uso narcótico. Rivera (1998) menciona que en el periodo colonial el consumo de coca llegó a ser considerado como el "talismán del diablo", puesto que había vuelto adicto a un gran número de clérigos, impidiendo la evangelización por parte de la iglesia católica. Igualmente, la disminución del trabajo de indígenas en las minas llevó a que el rey Felipe II promulgara el primer estatuto antinarcótico. Pese a ello, se menciona que sus efectos no fueron tan notorios, los cultivos de coca continuaron su expansión y España entró en el negocio del cultivo.

Posteriormente, en el periodo republicano, la coca llegó a ser considerada por algunos sectores políticos del país como una importante opción para la generación de ingresos en las zonas rurales dadas sus propiedades farmacéuticas. Hacia el año 1884 "distinguidos políticos como José María Samper veía la perspectiva económica que brindaba la coca en cuanto a sus atributos y posibilidades comerciales" (Rivera, 1998, p. 151). Durante esta época se realizaron una serie de recomendaciones técnicas para su siembra y manejo para que los grupos campesinos lograran una mayor producción de hoja en sus fincas. 
En las décadas siguientes, el cultivo adquirió una mayor importancia y su uso fue creciendo significativamente. A comienzos del siglo XX ya se había desarrollado una demanda significativa en aquellos países catalogados como desarrollados, entre estos los Estados Unidos de América, factor que dinamizó la transformación de la hoja de coca en un cultivo comercial orientado a la exportación en los países andinos (Madariaga, 2006). En 1947, debido a la crisis de los textiles en Colombia, el gobierno de Mariano Ospina Pérez desarrolló un plan de sustitución de importaciones para producir fibras nacionales (cáñamo) con destino a la industria textil; ello trajo el fomento del cultivo de marihuana con tan mala suerte que este no sirvió para la producción de fibras, pero sí para el consumo como psicoactivo. Esto llevó a que se promulgara el decreto 896 de marzo de 1947 mediante el cual se prohibía cultivar marihuana, pero también coca, situación que conduciría a la movilización de terratenientes, grupos políticos y comerciantes del departamento del Cauca que obligaron a la derogación de dicha normativa. Manzano, Muñoz et. al. (citados en Rivera, 1998) afirman que "El decreto 896 ha causado profunda inquietud en agricultores caucanos. Gran parte de habitantes del sur del Cauca dedicase al cultivo de la coca (...) Como vecinas regiones productoras de coca y en nombre de diez mil (c) respetuosamente pedimosles derogatoria del decreto" (p. 153).

Como lo plantea el mismo Rivera (1998), ya para la década del cuarenta los cultivos de coca se habían convertido en un negocio que tal vez dejaba unas sumas importantes de ganancia económica, prueba de ello está en que no solo el campesinado protestó contra el estatuto antinarcóticos, sino que allí también se involucraron un importante sector de terratenientes y comerciantes caucanos.

Tras la caída del negocio de la marihuana, se facilitó el paso a la llamada "bonanza coquera" hacia finales de la década del setenta (Díaz y Sánchez, 2004), con lo cual se afirmaron los grupos narcotraficantes de la época y de la década del ochenta, años en los cuales se consolidaron grandes organizaciones como el Cartel de Medellín, Cali, Central, el de la Costa y los Santanderes, quienes además de la producción de drogas vieron la necesidad de tener un aparato armado paraestatal para proteger su negocio. Como lo menciona Puentes (2008):

Los colombianos no tuvieron el control de rutas, ni de comercio al por mayor o de las redes de distribución en los Estados Unidos. El volumen del producto era muy grande y su transporte era costoso. (...) Los norteamericanos empezaron a cultivar marihuana de una calidad más 
fuerte en cultivos hidropónicos. El ciclo de consumo cambió y los consumidores prefirieron drogas más fuertes como la cocaína (...) el gobierno de Estados Unidos intensificó su guerra contra las drogas y esto afectó fuertemente los grandes cargamentos de marihuana. (...) Por la brevedad del boom de la marihuana no se formó una mafia colombiana a su alrededor, sin embargo, el negocio dio pie a la consolidación de las grandes mafias de la cocaína en Colombia. (p. 2)

El auge de la transformación de las hojas de coca en pasta de coca estuvo también acompañado de los denominados Cuerpos de Paz norteamericanos de la década del setenta; "estos no solo eran consumidores de sustancias psicotrópicas sino que también enseñaron a procesar la milagrosa cocaína" (Rivera, 1998; Spitaletta, 2015). Si bien es cierto que anterior al desarrollo de todo un conocimiento y tecnología para el procesamiento de hoja de coca en Colombia la producción de cocaína se realizaba a partir de la importación de base de coca desde Perú y Bolivia, con la intervención de los Cuerpos de Paz se aceleró la consolidación de la cadena de producción de dicho alcaloide (Rivera, 1998).

En el caso del departamento del Cauca, el desarrollo de la economía coquera estuvo muy ligada a la crisis de los precios del café durante la década del ochenta. "Una crisis política generada por la ruptura del pacto de cuotas ${ }^{2}$, abre paso a la expansión por gran parte del territorio colombiano de un cultivo no deseado para el Estado que logra expandirse y consolidarse eficazmente" (Daza, 2016, p. 101). La crisis de los precios del café generó una desaceleración de este renglón de la economía nacional dejando a su paso una suma importante de mano de obra desocupada que tuvo que regresar a sus regiones de origen. Los cultivos de coca iniciaron su expansión no precisamente en aquellos territorios dedicados al cultivo del café, sino en aquellos departamentos en donde las condiciones de difícil acceso a la fuerza pública y condiciones climáticas adecuadas propiciaban ventajas comparativas para el cultivo (Daza, 2016). Luego, zonas apartadas de los centros urbanos se constituyeron en focos de diseminación de estos cultivos.

En los años siguientes los grupos guerrilleros encuentran en este negocio un importante renglón para la generación de ingresos económicos; sin embargo,

2 Entre los años 1935 y 1940 Colombia exportaba tres millones de sacos de café. En 1940 se suscribe el Pacto Internacional de Cuotas, que tenía como ejes centrales la implementación de un precio y de una cantidad fija. Mediante el precio fijo los productores contaban con un costo de producción rentable y con un mercado definido gracias a la cantidad fija de exportación. Estos dos ejes hacían del café un negocio seguro, que carecía de riesgos de pérdida, y donde los cafeteros contaban con un $100 \%$ de probabilidades de vender el producto garantizando la ganancia. (Urrea, 2013, párr. 3) 
se presentarían dificultades que deterioraron los vínculos entre los grupos subversivos y los narcotraficantes del momento. Con la autofinanciación de grupos paramilitares y el vínculo de diferentes personajes de la vida política en el negocio de la cocaína, se dio paso a toda una nueva oleada de violencia en los campos y ciudades del país y a numerosos escándalos en el aparato político nacional en donde muchos personajes de la vida política se han visto involucrados en casos de paramilitarismo y narcotráfico. Puentes (2008) afirma que la nueva clase terrateniente involucrada en el mercado ilícito de cocaína se adueñó de un $11 \%$ de las zonas rurales del país agudizando aún más el proceso de concentración de la propiedad de la tierra en el campo, situación que incrementó la necesidad de seguridad privada y el enfrentamiento entre los grupos armados de izquierda y los carteles con sus nuevos ejércitos paramilitares.

La presencia y auge de los cultivos de coca data desde mucho antes del periodo colonial, primero como uso medicinal y como parte de la misma cultura indígena dentro de sus rituales sagrados, y luego como instrumento de dominación por parte de los grupos invasores europeos. El descubrimiento de sus propiedades farmacéuticas aceleró aún más el crecimiento de áreas cultivadas, con lo que llegó a ser considerada como un posible cultivo para el desarrollo económico en zonas rurales del país; luego, su uso como narcótico y posterior prohibición condujo al desarrollo de un mercado clandestino a través del cual se amasaron grandes capitales de dinero.

Otra situación que se da es que lo ilícito, en este caso los cultivos de coca, no aporta ningún tipo de ingreso económico a las arcas nacionales; durante el periodo colonial las ganancias fueron a parar al Estado Real Español, ya en la era republicana las ganancias fueron monopolizadas en las manos privadas de los grupos narcotraficantes. De igual manera, la condición de ilegalidad fue determinada inicialmente por el Estado español y luego en la era republicana por los gobiernos de turno; posteriormente, propagandas que en su momento circularon en los medios de comunicación nacional como "la coca, la mata que mata", pretendieron justificar que la maldad de su uso estaba en el cultivo mismo y no en las prácticas de transformación promovidas desde el mismo gobierno norteamericano, situación ante la cual las comunidades no tardaron en reaccionar y obligaron a la abolición de este tipo de tergiversaciones que desde los medios de comunicación estatal se promovieron, desdibujando por completo la importancia que esta planta ha representado y aún representa para las culturas indígenas. Como lo expresa Molano en una columna del periódico el Espectador del mes de febrero de 2009: 
No hay ninguna mata que mate, o por lo menos que mate por contacto directo. Ni siquiera el borrachero (...) mata a la gente. No hay ninguna mata a la que se le pueda echar la culpa de la guerra. Solo en las mentes del presidente y de algunos militares cabe la tesis de que hay "matas de cocaína", que es como decir que hay árboles de aspirina. Desde hace miles de años, la coca es un arbusto sagrado para la mayoría de comunidades indígenas; lo cultivan las mujeres, y sus hojas secas, mezcladas con hojas de yarumo tostadas o con conchitas molidas, son consumidas en forma de ritual por los hombres adultos. (párr. 3)

Finalmente, hay que señalar que el desarrollo de toda una economía alrededor de los cultivos de coca en Colombia tiene unas causas profundas que aún persisten, fenómenos como la concentración de la propiedad de la tierra y el desplazamiento forzado de masas campesinas a las zonas de montaña, en el denominado periodo de la violencia, condujeron a la profundización de las condiciones de pobreza rural en el país. Si a esto se le suma la precariedad institucional del Estado y la ausencia de una verdadera política agraria dirigida al desarrollo de condiciones para una economía lícita, como también el involucramiento de los grupos armados legales e ilegales en el jugoso negocio del narcotráfico, tenemos como resultado una historia llena de corrupción, despojo y falta de presencia institucional frente a sectores sociales que, ante la imposibilidad de contar con condiciones reales que permitan desarrollar otro tipo de actividades económicas para el sustento, terminaron y aún viven del cultivo de la hoja de coca. Prueba de ello está en que una importante masa de campesinos en economías parcelarias dependen de este cultivo y, por tanto, en este negocio no participan exclusivamente los grandes terratenientes y capos de la droga; al contrario, un importante sector campesino en muchas ocasiones en condiciones de subsistencia, finalmente se ha visto obligado a insertarse en este tipo de actividades, ante la ausencia de una política integral que reconozca la importancia de la economía campesina en la garantía de la soberanía alimentaria nacional. En esta realidad es posible afirmar que:

Los cultivos ilícitos se convierten en un factor generador de empleo e ingresos, con diferentes alternativas laborales que van desde la siembra, la recolección de hoja, la fumigación, el procesamiento de la hoja en pasta y la comercialización. A este movimiento se integran el comercio de los insumos químicos necesarios para el control de plagas y malezas, la transformación de la hoja en base y clorhidrato de cocaína, el comercio de la gasolina, los restaurantes, el transporte, los bienes de consumo y la prostitución. (Ferro et al., 1999, p. 6) 


\section{El Plateado, pueblo de grupos colonos y aventureros}

En el flanco occidental de la misma cordillera, hacia el sur occidente del departamento del Cauca, se encuentra localizado el municipio de Argelia (Figura 1), conformado por trece corregimientos de los cuales hace parte el corregimiento El Plateado. Este último es una de las regiones más apartadas en términos de distancia de la cabecera municipal, por lo que es necesario, para su llegada, el paso obligado por las localidades de El Mango, Sinaí y Puerto Rico.

A nivel departamental el municipio de Argelia se encuentra entre las regiones más apartadas de la ciudad de Popayán (capital departamental) y en su trayecto desde la capital caucana se debe pasar por los municipios de Timbio, Rosas, El Bordo Patía y Balboa. El recorrido a través de la vía panamericana ${ }^{3}$ desde la ciudad de Popayán se ve interrumpido en las planicies de El Estrecho Patía, lugar en el cual se empieza el abandono del gran valle del río Patía y se da comienzo al ascenso en las pendientes de las montañas de la cordillera occidental que conducen al municipio de Balboa, cambiando por completo las condiciones climáticas, el paisaje y la cultura de la población.

La comodidad de la vía pavimentada se suspende a la salida del municipio de Balboa, en donde el polvo y la irregularidad de una vía destapada ${ }^{4}$ conduce finalmente hasta el municipio de Argelia. A su llegada, los cultivos de café, plátano y otros denominados de pan coger, característicos de las economías campesinas, dan la bienvenida en lo enmarcado desde el Estado como economías legales. No se debe esperar mucho tiempo para notar cómo cambia por completo el paisaje y la economía en el territorio argelino, los cultivos de pan coger dan paso a extensas áreas en monocultivos de coca que se extienden a lo largo y ancho de la carretera, y la población poco a poco se va sumergiendo en las diferentes actividades y dinámicas de una economía ilícita en donde el conflicto social y armado ha impactado profundamente la vida y la historia de sus habitantes.

\footnotetext{
Vía terrestre internacional que comunica a casi todos los países del continente americano.

Carretera que se caracteriza por no estar pavimentada, en su lugar este es reemplazado por material de roca al cual se le denomina balastro
} 


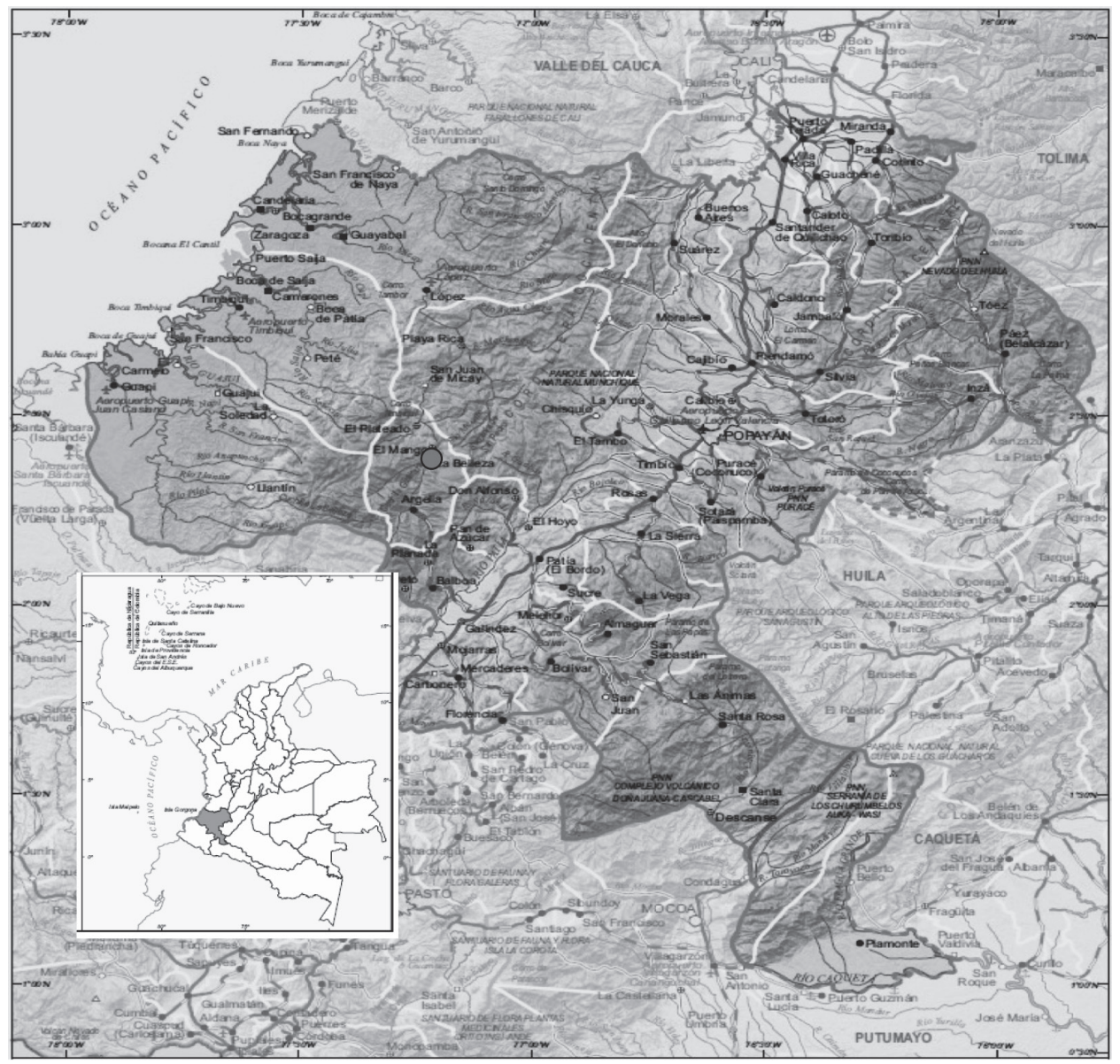

Figura 1. Localización geográfica del corregimiento El Plateado en el departamento del Cauca. (Instituto Geográfico Agustín Codazzi, 2012).

A su paso por la vía que conduce al corregimiento El Plateado, los avisos, pancartas y murales alusivos a los grandes jefes de las FARC-EP como Manuel Marulanda Vélez, Jacobo Arenas, Alfonso Cano y líderes revolucionarios cubanos, como Ernesto el Che Guevara, exponen un panorama en el cual la confrontación armada entre las fuerzas militares del Estado y los grupos guerrilleros ha sido algo inevitable. Prueba de ello está en el deterioro de viviendas de corregimientos como el Mango y Sinaí, en donde el impacto de las balas ha generado daños materiales y cicatrices que también están en la memoria de sus pobladores.

Si bien el municipio de Argelia se crea mediante la ordenanza 02 de 1967, algunos escritos mencionan que la historia del corregimiento data de varios años atrás como producto de la vida y ambición de grupos colonos aventureros que llegaron a estas regiones montañosas. 
Así, desde principios de la década de 1940 se inicia un proceso de movilización de grupos colonos hacia las profundidades de la cordillera occidental en donde se ubica el territorio de El Plateado. Pese a que en estos años en el país se vivió la época de confrontación violenta entre los partidos políticos liberal y conservador, hecho que desencadenó en el desplazamiento de comunidades campesinas liberales de sus territorios con la consecuente conformación de los primeros grupos armados que veían en las guerrillas una opción para la toma del poder, inspirados en la experiencia de la revolución cubana, el proyecto de fundación de una nueva población según uno de sus coautores, obedeció más a una iniciativa de grupos aventureros que a un proceso inducido por la misma violencia vivida en el país, así queda registrado en algunos relatos. "Este relato (...) se diferencia de los actuales desplazamientos en que este no sucedió por la intervención de la violencia, sino más bien por el afán aventurero que albergamos algunos hombres y que hace de nuestra vida el motor de nuestros afanes" (Zapata, 2004, p. 12).

De esta manera, el origen del corregimiento El Plateado se da a partir de la aventura de Miguel Zapata, un hombre nacido en una comarca del Municipio de El Bordo Patía llamada Guadualito, quien, en 1943, junto con Felipe Rosero e Isaac Navia inician su proyecto aventurero, luego se unirían otros personajes como Gregorio Bravo, Jovino Solarte, Epifanio Muñoz, José Gutiérrez y Manuel Zapata (Zapata, 2004). No obstante, si bien la fundación del corregimiento se da solo hacia 1950, durante el transcurso de los siete años después de la partida de Zapata y sus acompañantes desde las planicies del Valle del Patía pasarían por los territorios del actual corregimiento de El Sinaí, La Playa, La Belleza y finalmente El Plateado. Solo en este último encontraron las mejores condiciones para instalarse y materializar finalmente el pueblo que soñaban.

En 1945 (...) se organiza la expedición que partiendo de La Belleza explora las riveras del Rio [sic] Pinche, donde localizan la llanura que cinco años más tarde se convertiría en el pueblo de El Plateado, nombre que se derivó del metal del mismo nombre que descubriera en el Río Plateado un gringo de apellido Vanín. (Zapata, 2004, p. 17)

Nos llamó la atención no solo la topografía del terreno y la ubicación estratégica de la zona sino también la bonanza de recursos naturales, flora y fauna. (...) Pero lo que terminó por convencernos fue el agua pura y cristalina del río Plateado. (Zapata, 2004, p. 26) 
Pese a la iniciativa como proyecto aventurero de fundación de una nueva población, no puede negarse que los sucesos derivados en el país después de la muerte de Jorge Eliecer Gaitán también llegaron hasta los territorios del actual municipio de Argelia, eventos que acelerarían el proceso de ocupación del territorio divisado como punto estratégico.

En 1948 con la muerte del caudillo Jorge Eliecer Gaitán se desató una profunda crisis social en el país la cual llegó hasta la población de Argelia. (...) Esta situación condujo a que la población empezara a desplazarse al municipio de El Tambo y otras regiones, abandonando sus pertenencias y otros menos afortunados perdieron sus vidas. (...) Fue así que Miguel Zapata, Samuel Medina (...) y otros habitantes vieron que la única solución era internarse en la selva para empezar a poblar. La situación se tornaba difícil por la carencia de caminos, pero esto no impidió seguir con nuestro proyecto. (Zapata, 2004, p. 33)

Lo anterior se ratifica a través de diálogos sostenidos con una habitante de la localidad, quien manifiesta que la confrontación de los partidos políticos liberal y conservador durante la década del cuarenta generaron condiciones para el desplazamiento de Miguel Zapata junto con sus acompañantes hacia territorios del actual corregimiento de El Plateado.

Esto comienza en 1948 cuando inició la guerra entre los liberales y los godos. Entonces mi mamá, mi mamá era muy liberal, entonces porque ella no quiso jurar bandera y unirse a ellos prefirió huirse por acá con don Miguel Zapata, que era primo de nosotros. Por eso se vino mi mamá a meterse aquí y descubrieron esto por la violencia, por la opresión de los godos hacia los liberales, así era la vida en ese tiempo. (Habitante de la zona, comunicación personal el día 9 de septiembre de 2016)

Como todo proceso de colonización, la tala y quema del bosque daría luego paso a la siembra de semillas de cultivos de pancoger como maíz, yuca, plátano, caña, arroz, café, cacao, entre otros, para garantizar la alimentación de la nueva población que empezaba a florecer. Pero los grupos colonos que llegaron a esta zona no serían los primeros en habitar el territorio de El Plateado. Algunos documentos señalan que el corregimiento estuvo habitado por indígenas guepies, telembies, y barbacoas hasta la década del cuarenta (Bolaños, 2013), hecho que corrobora el mismo Zapata (2004): "Lo más llamativo de todo fue el hallazgo de rastros que nos indicaban que estas tierras habían sido habitadas en otros tiempos por alguna cultura prehispánica, encontramos joyas, piedras labradas y uno que otro utensilio de hierro" (p. 27). 
No sería necesario que pasaran muchos años para que habitantes de otros lugares empezaran a llegar a la nueva población que se estaba fundando, con ello aumentaría también las necesidades de tierra y, por supuesto, la necesidad del desarrollo de estrategias para garantizar servicios básicos como el acceso al agua potable que años después daría paso para el inicio de los primeros intentos de construcción del acueducto comunitario, hoy Asociación de Usuarios de Servicios Públicos de El Plateado. "Después de nosotros y nuestras familias fue llegando gente procedente de diferentes regiones que ocuparon terrenos baldíos o compraron a otros colonos llegados antes que ellos. La mayoría de ellos venían de San Juan" (Zapata, 2004, p. 37). De esta manera, lo que inicialmente era una vasta zona llena de vegetación con las características particulares de la selva húmeda tropical, a través de la intervención de la mano del grupo colono fue dando paso a pequeñas áreas con cultivos de pan coger, mientras que alrededor de lo que actualmente es el parque central del corregimiento se iban levantando día a día las construcciones que servían de vivienda para las familias de aquella época.

\section{Llegada de los cultivos de coca al corregimiento El Plateado: El paso de economías lícitas a economías ilícitas}

Tendrían que pasar un poco más de 20 años después de la llegada de los primeros habitantes para que empezaran a aparecer las primeras plantaciones de coca con fines de producción de alcaloides en El Plateado. Sin embargo, antes de este proceso, según habitantes de la zona, existieron prácticas culturales heredadas quizá de las culturas indígenas como el uso de las hojas de coca secas para masticar. Por lo tanto, al igual que en la historia nacional, la coca inicialmente cumplía fines eminentemente culturales a nivel local y poco después se constituyó en el cultivo de mayor importancia económica en la zona.

Hay que señalar que, a nivel nacional, desde la década del setenta, se da inicio a la implementación de políticas para la erradicación de cultivos ilícitos, situación que también incidiría en las dinámicas internas frente a la movilidad de los cultivos en el territorio nacional. La producción de cultivos ilícitos en regiones como la Costa Atlántica fue dando paso a la apertura de nuevas áreas cultivas en el sur de Colombia, fenómeno que directamente incidió en los inicios de los cultivos de coca en el Corregimiento de El Plateado. Walsh, Sánchez y Salinas (2009) mencionan que los procesos de fumigación desembocaron en la apertura de nuevas áreas cultivadas en el sur del país, especialmente en departamentos como el Cauca. 
El impulso a las fumigaciones en la región de la Costa Atlántica, por una parte, y las acciones adelantadas para combatir la producción de cocaína en Bolivia y en el Perú, por la otra, generaron el traslado de las plantaciones de hoja de coca hacia Colombia (...) así mismo, los cultivos de marihuana migraron hacia Cauca y Meta. (p. 35)

Frente al caso de los cultivos de coca con fines ilícitos en el corregimiento de El Plateado, según pobladores, durante la década del setenta empiezan a aparecer las primeras plantaciones que poco a poco fueron generando profundos cambios socioculturales en la región.

La coca empezó a aparecer a finales de los setentas así en cantidad, antes si había pero la utilizaban para masticarla, eso la tostaban y la masticaban (...) se tenían matas de coca pero eran pocas en algunas fincas, los días domingos sacaban a vender en el mercado una o dos libras de hoja seca para masticar. Ya hacia finales de los setentas fue que empezó a aparecer la coca con fines industriales, es decir para procesar y producir cocaína. (Habitante de la zona, comunicación personal, 16 de febrero de 2016)

De esta manera, según los relatos de habitantes, hay coincidencia entre los años de expansión de los cultivos de coca con fines ilícitos a nivel nacional y el inicio del desarrollo de una cultura local asociada a los cultivos de coca en el corregimiento. Las primeras áreas cultivadas iniciaron en sectores distantes como La Emboscada y desde allí la tala y quema de bosques fue dando paso a nuevos paisajes verdes que se convirtieron en el sustento económico de la región. Se menciona que inicialmente los cultivos de coca llegaron a municipios como Bolívar, ubicado al sur del departamento del Cauca y desde allí posteriormente se empezó a introducir semillas a la región de El Plateado.

Lo que sé es que primero la coca la cultivaban en Bolívar y desde allí se trajo las primeras semillas para el corregimiento de El Plateado, las primeras fincas productoras de coca fueron donde los Uribes, los Gonzales y los Quinayaces; abajo en la Emboscada. Eran tres fincas en donde se empezó el cultivo de la coca y después se expandió por todo lado. (Habitante de la zona, comunicación personal, 16 de febrero de 2016)

Otro campesino que ha vivido durante cincuenta y cinco años en el corregimiento corrobora también la misma información, agregando que desde el municipio de Bolívar venían personas que ya sabían del proceso de extracción de base de coca para enseñarle a los nuevos cultivadores el arte del procesamiento de las hojas, así queda expresado en una de sus entrevistas: 
Los primeros en traer la coca a El Plateado fueron los Uribes y los Gonzales en el año 78. Desde Bolívar venía la persona que enseñaba a procesarla y después del 81 fue cuando la gente se destapó a sembrar coca, todos empezaron a sembrar la famosa pajarita. (Campesino de la zona, comunicación personal, 19 de noviembre de 2015)

En otros relatos se menciona que a nivel municipal los cultivos de coca inicialmente se establecieron en el corregimiento de Sinaí, donde presuntamente una persona de origen australiano sería quien enseñó a los habitantes el arte de procesar las hojas de coca. Después de este proceso tuvo lugar el plantío y expansión de los cultivos de coca en el corregimiento El Plateado, así lo narra una docente de la localidad.

La primera bonanza coquera fue en el Sinaí y acá en El Plateado apenas se comenzaba a ver coca (...) ¿sabe por qué en el Sinaí? Porque en el Sinaí había los que mambiaban la coca, había habido varios que tenían ese vicio y entonces ellos tenían sus matas de coca y entonces por eso los primeros ensayos que hicieron en los laboratorios había sido en Sinaí ... entonces ahí fue que comenzó a surgir, inclusive dicen que allí fue un australiano que vino a enseñarles a hacer el polvo, la mercancía, el bazuco. Dicen que en ese tiempo una arroba de coca llego a valer como doscientos mil pesos. (Docente, comunicación personal, $11 \mathrm{de}$ abril de 2016)

A nivel local, con los cultivos de coca no solo se empezó a reemplazar la base productiva agrícola, sino también algunas iniciativas de producción pecuaria como la cría de ganado bovino y cerdos de engorde, ambos sistemas caracterizados por un manejo tradicional en donde los animales permanecían sueltos para alimentarse de pasturas que crecían de manera natural y también de residuos de cocina o cosechas para el caso del ganado porcino. Si bien no existen datos que den cuenta de los volúmenes de producción y el número de personas que empezaron a cambiar sus sistemas productivos, es posible hacerse una idea de los cambios que se dieron en esta materia a partir de algunos relatos de sus habitantes.

En esa época había ganado, por aquí cultivaban arroz, de aquí pa bajo todo esto era arrocero, por acá también había cacao, como en ese tiempo eran pocas las familias también (...) el cacao hubo una época en que fue bueno (...) uuuu, el cacao movió plata como en los años 70 tal vez (...) se vendía en grano (...) una trilladora si hubo aquí en esta esquina. En ese tiempo había ganado, se criaban mucho los marranos, 
todas las fincas mantenían su cría de marranos pero sueltos, también se cultivaba caña y se sacaba panela. (Habitante de la zona, comunicación personal, 16 de febrero de 2016)

Con la expansión de los cultivos de coca se fue creando toda una cultura que terminó por reemplazar por completo la anterior base productiva y, a su vez, las relaciones de convivencia en la comunidad. Frente a este último aspecto, con el desarrollo de una economía del narcotráfico llegaron también los grupos armados pertenecientes a las Fuerzas Revolucionarias de Colombia (FARC-EP) y, posteriormente, guerrillas pertenecientes al Ejército de Liberación Nacional (ELN). Esta situación generó un escenario de tensión y violencia frente al control territorial por la disputa de poderes entre los grupos armados insurgentes y las fuerzas militares del Estado, situación que ha cobrado muchas vidas con el consecuente terror y miedo en la población. Como lo señala Gómez y Buendía (citados en Madariaga, 2006):

Con el narcotráfico se catapultó la capacidad militar de los grupos armados, se acentuó su lógica rentista, se criminalizaron sus acciones, se erosionó la legitimidad del sistema político y se internacionalizó la confrontación. En términos generales, los grupos armados ilegales participan en el negocio de las drogas en todas sus etapas: vigilando cultivos, mediando en las relaciones patronales de los mismos, actuando como intermediarios locales, y sobre todo cobrando el impuesto de 'gramaje', un porcentaje del valor de la coca comercializada cuya proporción varía según la zona y el actor y que puede ser cobrado en dinero o en 'mercancía'. (p. 9)

Toda esta realidad no ha estado alejada de los procesos de violencia vividos en el corregimiento de El Plateado y sus alrededores a partir de la siembra de coca en su versión de ilegalidad. El salto de una economía de subsistencia a una economía del narcotráfico cambió la base productiva local y a su vez las condiciones de vida de la comunidad que generó toda una transformación sociocultural en los espacios locales.

En la memoria colectiva de habitantes se relata que antes de los cultivos de coca la vida se tornaba difícil, no había vías de acceso y mucho menos un alto nivel de ingresos económicos en la población, el número de familias era reducido y existían unas buenas relaciones de convivencia entre habitantes. Con el desarrollo de una nueva estructura económica en el marco de lo ilícito, los flujos de población que llegaban a la comunidad con la ambición de amasar importantes sumas de dinero empezaron a generar un encuentro/ 
desencuentro cultural entre habitantes provenientes de diferentes regiones y los grupos de pobladores que ya se hallaban instalados en el corregimiento $y$, a su vez, se empezaron a generar otras dinámicas de vida al interior del territorio. En diálogos con una exdocente que vivió su juventud en El Plateado y habitantes que nacieron en el Corregimiento de El Mango, se rememoran algunos recuerdos de la vida en esos tiempos.

Yo llegué en el año de 1983, la vida en ese tiempo era como regular (...) en ese tiempo no había vía de comunicación terrestre, habían solo caminos de herradura, estos eran estrechos y en época de invierno se dañaban, eso se volvían unos lodazales (...) aquí en ese tiempo todo era caro ya que todo lo traían de afuera, venían comerciantes desde Argelia y también después desde Popayán, pero todo lo entraban en bestia (...) para esa época la carretera solo llegaba hasta Tambolargo, de allí tocaba a pie. En esa época la gente no tenía ningún tipo de servicio, el agua la tomaban de una pila que había en el centro de los que hoy es el parque y para jabonar tenían que ir al río. (Exdocente, comunicación personal, 4 de febrero de 2016)

La vida en ese tiempo era dura, no había casi plata, en ese tiempo en época de cosecha la gente se iba a coger café a Argelia, Bolívar, El Valle, Quindío. Los papás de nosotros se iban y nos dejaban acá, de allá traían ropa, lo necesario (...) ahora los papeles se cambiaron, de allá vienen a cosechar hoja los raspachines. (Habitante de la zona, comunicación personal, 16 de febrero de 2016)

Los años siguientes estuvieron caracterizados por el aumento progresivo de la población que migraba a la región con el fin de establecer sus cultivos o en calidad de jornaleros para insertarse en las diferentes actividades de la nueva actividad económica. Con el paso del tiempo, el número de familias fue aumentando y así mismo la velocidad con que fue depredada la montaña para su reemplazo por cocales. Si bien al principio algunos habitantes se dedicaron a vender su fuerza de trabajo y en el caso de las mujeres a vender comida para la población que se insertaba en la nueva economía, poco a poco las dinámicas de vida se fueron transformando. Al ver que los cultivos de coca eran muy rentables, muchas personas empezaron a establecer sus propias plantaciones y, en el caso de las mujeres, estas terminaron insertándose en el mercado laboral en la cosecha de hoja.

Cuando llegaron los primeros cultivos la gente casi no le prestaban mucho atención, pero con el paso del tiempo se dieron cuenta que era 
un negocio muy lucrativo y cambiaron la forma de cultivos y la vida cotidiana en sí. Los hombres pasaron a ser cosechadores de hoja y las mujeres de vendedoras de comida a raspachinas también, después todos comprábamos la comida ya que los cultivos daban para esto. (Ex docente, comunicación personal, 4 de febrero de 2016)

Entrada la década del 90 a nivel nacional se intensificaron los programas estatales de lucha contra las drogas. Durante el gobierno de Cesar Gaviria "se establece por primera vez un marco regulatorio para las aspersiones a través del Consejo Nacional de Estupefacientes" (Walsh et al., 2009, p. 36). Luego, en el gobierno de Andrés Pastrana se colocó en marcha la política del Plan Colombia con el cual se buscaba, ante todo, detener el flujo de estupefacientes hacia el mercado de Estados Unidos. Luego de 15 años de aplicación sistemática de la política del Plan Colombia en el Estado Colombiano los resultados son irrisorios, las aspersiones con glifosato, más que contribuir a la reducción de los volúmenes de producción de cocaína en el país, lo que creó fue una serie de daños ambientales y sociales. Con el aumento del pie de fuerza armada estatal y paramilitar durante gobiernos como el de Álvaro Uribe Vélez bajo la política de Seguridad Democrática, se generó un escenario de persecución en donde gran cantidad de líderes del campesinado fueron fusilados por los grupos armados estatales y paraestatales para luego hacerlos pasar como los denominados falsos positivos. Como lo manifiesta Bustamante (2016), "El Plan Colombia hizo de nosotros los israelitas de América Latina”.

\section{Transformaciones socioculturales derivadas de la llegada de los cultivos de coca en el ámbito local}

En un estudio relacionado con los impactos de la coca en el departamento del Cauca, realizado por el economista Pedro Ancisar Daza (2016), se pueden extraer aportes importantes para la comprensión de la transformación socioeconómica caucana generada a raíz del tema de los cultivos de coca, radiografía que revela realidades locales como las vividas en el corregimiento de El Plateado, puesto que Argelia fue uno de los municipios incluidos dentro del escenario de investigación del autor en mención.

En materia social, la llegada de los cultivos de coca significó la desaparición paulatina de los cultivos tradicionales en las fincas campesinas para ser reemplazados por los cultivos de coca y con ello la manifestación de toda una cultura del dinero rápido, con la violencia y con una lógica de acumulación de dinero que no tiene en cuenta aspectos políticos, sociales y mucho menos ambientales. A su vez, el narcotráfico y la presencia de grupos armados, tanto del Estado como de los 
grupos subversivos y paramilitares, terminaron agudizando aún más las manifestaciones de un sistema capitalista de una manera más agresiva.

Otra situación particular como resultado de la expansión de los cultivos de coca fue la generación de condiciones para los flujos migratorios permanentes de población y aparición de raspachines, mulas, narcotraficantes y otros actores como nuevos sujetos vinculados a la nueva economía. De la misma manera, con el incremento de los ingresos económicos se desarrolló toda una cultura del consumo ostentoso en aquellas personas que derivan su sustento de lo ilícito, dejando en segundo lugar aspectos como la educación, puesto que para quienes están en el negocio de la coca existe la mentalidad de que es mejor dedicarse a conseguir dinero en lugar de formar capital humano.

Otro aspecto que se derivó en materia social fue la sustitución en cierto modo del papel del Estado como actor garante para el cumplimiento de los derechos de su ciudadanía, que pasó a ser reemplazado por la fuerza de los grupos ilegales, los cuales se constituyeron en las fuerzas de control social en el territorio. Al respecto, Daza (2016) manifiesta lo siguiente:

No importa si los grupos armados mantienen sus vínculos de forma directa o no, lo que interesa son los efectos generados por estos en la sociedad. Al existir escasa presencia de la fuerza legítima del Estado, llámese Policía o ejército, los grupos ilegales encuentran las vías para ejercer el control sobre los territorios abandonados por parte del Estado. El mezclarse la ausencia de la fuerza legítima con una fuente de financiamiento, estos grupos ilegales se fortalecen tanto que logran crear reglas o normas (instituciones) al interior de los municipios capaces de hacer creer o convencer a la población que la fuerza legítima son ellos, o por lo menos con su actuar son capaces de crear eso en la mentalidad de las personas, porque cuando la población requiere de justicia, no acuden a la autoridad legítima, acuden a estos grupos quienes por medio de su poder, solucionan los conflictos al interior de los municipios. Esto significa que, el Estado de alguna forma es reemplazado por el poder de los grupos ilegales y en este caso la fuerza legítima no tiene credibilidad y algunas normas nacionales de justicia se combinan con otras locales. (p. 226)

Las violaciones de derechos humanos y del derecho internacional humanitario como producto del conflicto armado que se desarrolló en la zona también fueron aspectos que marcaron la vida en la comunidad, aspecto en el cual las disputas por el control territorial entre los actores armados han generado la muerte de personas que no son parte directa de la guerra librada en el territorio. 
Los grupos ilegales a pesar de constituirse en la fuente de justicia para la población local, se manifiestan a través de la violencia, para estos grupos, la vida queda relegada a un segundo plano. Mantener el control territorial y el poder se han convertido en el objetivo de estos grupos y las disputas entre estos por el territorio hacen que la población civil salga mal librada de los conflictos, porque cuando determinado grupo pasa los límites estipulados por el otro e intenta cubrir una región que "le pertenece a otro", de inmediato la violencia se hace presente, la violación a los derechos humanos es la constante en este tipo de conflictos, en estos casos no importa el género, la religión, la edad, lo importante es el control territorial y con este desaparecen los principios humanos. (Daza, 2016, p. 226)

Otros aspectos que también han tenido lugar en el conjunto de cambios socioculturales están relacionados con el aumento del consumo de drogas, aparición de prostíbulos y exceso en el consumo de licor. En este último caso, habitantes de El Plateado recuerdan aquellos momentos de la bonanza coquera en donde la calle principal del corregimiento se llenó de sitios de venta de licores y prostíbulos donde saciaban su apetito sexual lo varones durante los fines de semana, situación que parece repetirse de nuevo en la actualidad, aunque en una menor magnitud.

Recuerdo que hubo una época en que la calle principal estaba llena de $\operatorname{chongos}^{5}(\ldots)$ sin mentirle, toda esa calle era llena de cantinas y prostíbulos. A veces salíamos los fines de semana con otro profe a tomarnos una cervecita y uno se encontraba en las calles a los pelados con la pistola en la cintura y en los bares si ni que se diga, todo mundo andaba armado. (Docente, comunicación personal, 4 de septiembre de 2016)

Hubo un tiempo que la prostitución se propagó como peste, en donde quiera que se asomaba habían chongos, eso habían como más de cuarenta en este pueblo, por esta calle habían como tres. Aquí también hubieron de esas chicas malas, ¡esas buenas que le dicen malas; , aquí en frente, enseguida, por donde quiera que pasaba (...) los que tenían esposas se volaban, se escondían, uno mismo los cubría. Cuando estaban aquí uno estaba piloso de que llegara la mujer para avisarles (...) eso se dañaban muchos hogares por esos motivos, más de uno no le importaba la esposa, no se tenía una buena tranquilidad. (Habitante de la zona, comunicación personal, 6 de septiembre de 2016)

5 Término con el cual en el escenario local se designa a los lugares en los cuales se promueve la venta de cuerpos femeninos a partir de su prostitución. 
En el plano económico, Daza (2016) manifiesta que con los cultivos de coca se generó un incremento en el PIB local y regional, lo cual desencadenó el aumento de la inflación que se evidencia con el incremento de los precios de los diferentes productos a nivel municipal, como consecuencia del alto flujo de dinero circulante en las economías locales. La inflación afecta en mayor proporción a las familias que no devengan sus ingresos de los cultivos de coca, generándose así condiciones de mayor desigualdad económica e inviabilidad de cualquier intento de cultivo tradicional por los altos costos de los insumos y mano de obra. Un docente y otro habitante de la localidad recuerdan esta situación de la siguiente manera:

En el colegio los muchachos andaban con plata, a veces habían unos que se perdían por dos o tres semanas, eran dueños de fincas, llegaban y le decían a uno: iprofe, la otra semana no voy a veniri. Uno ya sabía, ellos manejaban trabajadores en sus fincas y allí uno que hacía. Muchos se retiraban porque preferían irse a sembrar coca, es que a veces le preguntaban a uno: ¿Cuánto se gana usted profe? Eso le decían a uno, ¡no profe, eso me lo gano yo en un rato"! (Docente, comunicación personal, 4 de septiembre de 2016)

Eso era un tiempo, no recuerdo muy bien el año, en todo caso una bonanza buena (...) hubo lo que llaman la coca la pringa que tenía un precio bastante bueno y no habían tantas pestes como ahora. Uno con unas dos fumigas sacaba una buena cosecha y la coca era bastante cara, por ejemplo, la pringa llego a valer hasta cien o ciento diez mil pesos la arroba, ahora que, una arroba máximo llega a valer unos cincuenta mil pesos y se le gasta plata en cantidad en químicos. Yo siempre había cultivado y en esa época quedaba más platica pero también se malgastaba mucho (...) en qué no me gastaba el dinero de la coca, en los amigos, trago, muchas cosas, pasiando por la ciudad, pa ya y pa ca, eso era todo lo que hacía uno. (Habitante de la zona, comunicación personal, 6 de septiembre de 2016)

En la dimensión ambiental, la llegada de los cultivos de coca incrementó la tasa de tala de bosques; aumentó el deterioro del suelo, contaminación de fuentes hídricas y pérdida de biodiversidad como efecto del alto uso de agro-tóxicos e insumos químicos. A su vez, afectación de otros cultivos, fuentes hídricas, animales y comunidad en general como producto de las fumigaciones aéreas con glifosato y, desde luego, también la contaminación de ríos por vertimientos de residuos producto de la transformación de hojas de coca en los laboratorios ${ }^{6}$.

$6 \quad$ El laboratorio corresponde al sitio en el cual tienen lugar las diferentes actividades dirigidas a la transformación de las hojas de coca en base de coca. 
En el escenario político se generó persecución a líderes campesinos locales, pero también el fortalecimiento de la acción comunitaria a través de las asociaciones de campesinos y, en la actualidad, a través de la conformación de figuras para la resistencia colectiva como los comités cocaleros, la escuela cultural campesina, entre otros. Como resultado de la implementación de la política de Seguridad Democrática, que sumada a la aplicación de la política nacional del Plan Colombia y la legitimación de las guerrillas por parte de las comunidades como una forma de poder y regulación que empezó a ejercer control social en la zona, se agudizó aún más la crisis social debido al incremento del conflicto armado en el territorio. No se puede desconocer que el narcotráfico, a nivel regional, también ha estado presente en la financiación de campañas políticas y tal como lo expresa Daza (2016), "básicamente en los municipios con presencia de coca y grupos armados ilegales, ambos se encargan de poner alcaldes y concejales, esto significa que dineros ilegales permean las campañas electorales y de esta manera debilitan la institucionalidad" (p. 237).

\section{Apuntes finales en torno a los cultivos de coca en el escenario local}

Comprender las dinámicas de vida en lugares como el corregimiento El Plateado debe pasar por el necesario reconocimiento de las causas que han conducido al anclaje de economías ilícitas, como aquellas sustentadas en los cultivos de coca en el territorio desde hace varias décadas. Reconstruir la memoria colectiva de vida en el escenario local permite vislumbrar, por un lado, que no todo el tiempo la comunidad que habita este lugar ha dependido de los cultivos de coca; al contrario, en sus inicios la diversidad de cultivos y las relaciones comunitarias eran propias de las economías campesinas, que basaban sus relaciones sociales en lazos de solidaridad y cooperación. Su estrecha relación con el campo permitía la diversidad de cultivos y unos mayores lazos de unidad que favorecieron, en principio, colonizar tierras alejadas de la capital del departamento y fundar, con el tiempo, una nueva población que hoy para muchos líderes locales tiene todo el potencial para consolidarse como un nuevo municipio.

La llegada de los cultivos de coca significó para la localidad y sus alrededores la ruptura no solo de sus sistemas de producción, sino también de las relaciones sociales a partir del flujo constante de población atraídas por las promesas del narcotráfico, situación que no solo generó una crisis de identidad por el constante encuentro y desencuentro entre habitantes provenientes de diferentes lugares, sino también una crisis en la unidad familiar en la cual varios niños y niñas han sufrido el abandono de muchos de sus padres o madres, quienes dan prioridad a los cultivos de coca por encima del mismo cuidado de su progenie. 
Raspachines, mulas, narcos, guerrillas, paramilitares, militares del Estado colombiano, entre otros, son los nuevos actores que entraron a conformar parte del conjunto social, con vínculos directos o indirectos con las nuevas condiciones de la economía local y, a su vez, muchos de estos conformando los nuevos patrones de dominio territorial y control social. Comprender esta situación se constituye en un factor imprescindible para trazar pistas que permitan estructurar nuevas apuestas educativas que busquen resquebrajar la matriz cultural predominante en la zona, en donde el dinero fácil y la violencia se han incorporado o más bien naturalizado dentro de la vida social comunitaria.

Frene a esta situación, hacer memoria de la historia colectiva permite reconocer parte de esos conflictos sociales y cambios socioculturales que se han dado en el corregimiento, historia que es desconocida para gran cantidad de jóvenes y que necesita ser incorporada en espacios como los centros educativos, organizaciones de base campesina, entre otros, como aporte para la construcción de una identidad colectiva. Desde luego que la memoria reconstruida frente a la llegada y desarrollo de los cultivos de coca en el corregimiento El Plateado no agota por completo relatos y vivencias de la vida colectiva en el escenario local, puesto que no era parte del objetivo central del trabajo. Los elementos históricos aquí reconstruidos son un primer insumo para empezar a generar diálogos frente a ese pasado que ha caracterizado la vida en esta localidad. Como lo menciona Gómez (2002), "la identidad colectiva también viene dada por compartir rasgos culturales, una historia en común” (p. 18), situación que se torna compleja en el corregimiento precisamente por el encuentro/desencuentro de diferentes historias de vida, dada la alta movilidad poblacional que se vive en este tipo de territorios.

Recurrir un poco a los relatos directos de quienes han vivido en este sitio permite encontrar no solo una memoria cronológica de sucesos que se han dado en el territorio, sino también ese reencuentro entre el sujeto y su pasado del cual ha sido partícipe. Los sentimientos de satisfacción, angustias, miedos, admiración, nostalgias, entre muchos otros, son situaciones que permiten ver la manera en que esas historias no escritas, pero vividas, han impactado en la existencia personal y colectiva de quienes habitan este corregimiento.

La historia local, por tanto, no es una simple narración de hechos del pasado, más bien, es la posibilidad misma que tienen los actores directos para generar dinámicas organizativas que permitan reafirmar las historias narradas o, por el contrario, buscar otros rumbos que den un mayor sentido a la vida individual y colectiva. Desde luego que la posibilidad de cambiar el rumbo de la 
historia local no está solo en manos de los actores directos de esta misma, será necesario el acompañamiento del Estado con toda su institucionalidad y los recursos económicos suficientes para generar, en el tiempo, las condiciones materiales apropiadas y duraderas que permitan pensar en otras economías alejadas de lo catalogado como ilícito

\section{Referencias}

Bolaños, H. (2 de septiembre de 2013). Trabajando por la comunidad en Argelia Cauca. Diario Proclama del Cauca. Recuperado de http://www. proclamadelcauca.com/2013/09/trabajando-por-la-comunidad-en-argelia-cauca.html

Bustamante, D. (12 de febrero de 2016). El Plan Colombia o el olvido de Macondo. Revista Semana. Recuperado de http://www.semana.com/opinion/articulo/el-plan-colombia-o-el-olvido-de-macondo-opinion-dedavid-bustamante/460355

Daza, P. A. (2016). La coca y su impacto en la economía del Cauca. Popayán Colombia: Utopía Textos.

Díaz, A. M., Sánchez F. (2004). Geografía de los cultivos ilícitos y conflicto armado en Colombia. Centro de estudios de desarrollo económico, Universidad de los Andes Colombia. Recuperado de https://economia. uniandes.edu.co/assets/archivos/Documentos_CEDE/D2004-18.pdf

Ferro, J. G., Uribe, G., Osorio F. E., Castillo, O. L. (1999). Jóvenes, coca y amapola: Un estudio sobre las transformaciones socioculturales en zonas de cultivos ilícitos. Instituto de Estudios Rurales - Facultad de Estudios Ambientales y Rurales; Universidad Javeriana.

Gómez O. (2002). Memoria, identidad y cultura para el fortalecimiento organizativo. Corporación AVRE, Bogotá Colombia. Recuperado de http:// www.psicosocial.net/grupo-accion-comunitaria/centro-de-documentacion-gac/trabajo-psicosocial-y-comunitario/herramientas-investigacion-accion-participante/481-memoria-identidad-y-cultura-para-elfortalecimiento-organizativo/file

Instituto Geográfico Agustín Codazzi (IGAC). (2012). Mapa físico-político departamento del Cauca. Recuperado de http://geoportal.igac.gov.co/ mapas_de_colombia/igac/mps_fisicos_deptales/2012/Cauca.pdf 
Madariaga, P. (2006). Cultivos de coca, jóvenes y autoridades armadas en las montañas del sur de Colombia. Recuperado de http://biblioteca.clacso. edu.ar/ar/libros/becas/2007/cultura/madaria.pdf

Molano, A. (14 de febrero de 2009). La mata que mata. Periódico El Espectador. Recuperado http://www.elespectador.com/opinion/mata-mata

Parra, E. M. (2014). Desarrollo alternativo en el Perú, treinta años de aciertos y desaciertos. Revista Perspectivas Rurales Nueva Época, 12(23), 85-104.

Puentes, Á. M. (2008). El narcotráfico, antecedentes 1976 -1985 bonan$z a$ marimbera. Recuperado de http://www.verdadabierta.com/ la-historia-de-las-farc/243-la-historia/farc/139-el-narcotrafico

Rivera, L. G. (1998). Aporte de la historia de la coca en Colombia. Ensayos: Revista de la Facultad de Educación de Albacete, 13, 147-156. Recuperado de http://www.uclm.es/ab/educacion/ensayos/pdf/revista13/13_11. pdf

Spitaletta, R. (2015). Narcotráfico y posconflicto, el posconflicto puede resultar más complejo que el conflicto. Recuperado de http://www.elespectador. com/opinion/narcotrafico-y-posconflicto-columna-540161

UNODC - Oficina de las Naciones Unidas contra la droga y el delito (2015). Colombia, monitoreo de cultivos de coca 2014. Recuperado de https:// www.unodc.org/documents/crop-monitoring/Colombia/Colombia_ Monitoreo_de_Cultivos_de_Coca_2014_web.pdf

Urrea, S. (2013). El café, la crisis y el modelo de desarrollo. Recuperado de https://politicacolombiana2013.wordpress.com/2013/04/01/el-reciente-paro-cafetero-producto-de-la-crisis-que-atraviesa-el-sector-fue-elcentro-de-todas-las-miradas-algunos-de-manera-facilista-insistieronen-el-oportunismo-politico-y-en-la-utilizacion-de/

Walsh, J., Sánchez, G., Salinas, Y. (2009). La aspersión aérea de cultivos ilícitos en Colombia, una estrategia fallida. Oficina en Washington para asuntos Latinoamericanos WOLA, impreso en Colombia.

Zapata, M. (2004). El Plateado ayer, hoy y siempre, historia de un pueblo. Argelia Cauca, Colombia. 